OPEN ACCESS

Edited by:

Björn Tackenberg,

Philipps University of Marburg,

Germany

Reviewed by:

Elisabeth Gulowsen Celius, Oslo University Hospital, Norway

Trygve Holmøy,

Akershus University Hospital,

Norway

*Correspondence:

Gustavo Saposnik

saposnikg@smh.ca

Specialty section: This article was submitted to Multiple Sclerosis and

Neuroimmunology,

a section of the journal

Frontiers in Neurology

Received: 08 February 2018

Accepted: 06 March 2018

Published: 20 March 2018

Citation:

Saposnik G and Montalban X (2018)

Therapeutic Inertia in the New

Landscape of Multiple

Sclerosis Care.

Front. Neurol. 9:174.

doi: 10.3389/fneur.2018.00174

\section{Therapeutic Inertia in the New Landscape of Multiple Sclerosis Care}

\author{
Gustavo Saposnik ${ }^{1,2 *}$ and Xavier Montalban ${ }^{1,3,4}$ \\ ${ }^{1}$ Outcomes and Decision Neuroscience lab, Division of Neurology, Department of Medicine, St. Michael's Hospital, University \\ of Toronto, Toronto, ON, Canada, ${ }^{2}$ Laboratory for Social and Neural Systems Research, Department of Economics, \\ University of Zurich, Zurich, Switzerland, ${ }^{3}$ Neurology-Neuroimmunology Department, Neurorehabilitation Unit, Multiple \\ Sclerosis Centre of Catalonia (Cemcat), Barcelona, Spain, ${ }^{4}$ Center for Multiple Sclerosis, St. Michael's Hospital, University of \\ Toronto, Toronto, ON, Canada
}

The landscape of multiple sclerosis (MS) treatment is constantly changing. Significant heterogeneity exists in the efficacy and risks associated with these therapies. Therefore, clinicians have the challenge to tailor treatment based on several factors (disease activity level, risk of progression, individual patient preferences and characteristics, personal expertise, etc.), to identify the optimal balance between safety and efficacy. However, most clinicians have limited education in decision-making and formal training in risk management. Together, these factors may lead to therapeutic inertia ( $\mathrm{TI})$; defined as the absence of treatment initiation or intensification when therapeutic goals are unmet. TI may lead to suboptimal treatments choices, worse clinical outcomes, and more disability. This article provides a succinct overview on factors influencing TI in MS care.

Keywords: therapeutic inertia, multiple sclerosis, decision-making, humanized antibodies, outcomes

The reason men oppose progress is not that they hate progress, but that they love inertiaElbert Hubbard (writer 1859-1915)

The landscape of multiple sclerosis (MS) has changed over the last few years. Clinicians and patients welcomed the introduction of disease-modifying therapy (DMT) for MS in the mid-1990s. Injectable agents, all with rather similar risk-benefit profiles, dominated MS care for over a decade (1). The approval of Natalizumab - a recombinant monoclonal antibody that reduces signs of disease activity and inflammation-for MS treatment marked a paradigm change with the introduction of a more effective treatment option, but also the realization of the risks associated with modulation of the immune system (e.g., risk of PML) (2). More recently, the introduction of oral agents has opened yet another avenue for patients and clinicians. Currently, there are over 12 DMTs available to treat MS, with varying availability around the world. Significant heterogeneity exists in the efficacy and risks associated with these therapies. Therefore, clinicians have the challenge to tailor treatment based on (i) disease activity level, (ii) risk of progression, (iii) individual patient preferences and characteristics, and (iv) personal expertise, to identify the optimal balance between safety and efficacy. Based on the aforementioned factors, neurologists caring for MS patients face important choices in each medical encounter: (1) continue with the same management, (2) initiate or escalate therapy for a more effective or safer agent, or (3) consider a reassessment within months under the uncertainty of the current status of the patient. As a result, therapeutic inertia (TI)-first coined by Okonofua (3) for management of patients with hypertension and diabetes-emerged to define the absence of treatment initiation or intensification in patients when therapeutic goals are unmet. Physician factors (e.g., low tolerance to uncertainty, status quo bias) are considered to be the main contributors to TI (explaining at least $50 \%$ of TI) but remain poorly studied (Table 1) (4). One of the invoked explanations is physicians' limited training in risk management and formal learning 
TABLE 1 | Factors influencing therapeutic inertia in multiple sclerosis (MS) care. ${ }^{\text {a }}$

\begin{tabular}{|c|c|c|}
\hline Physicians factors & Patient-related factors & Health-care factors \\
\hline - Failure to set clear goals & - Demographic (e.g., older age) & - Lack of guidelines \\
\hline - Errors in risk assessment & $\begin{array}{l}\text { - Misinterpretation of clinical activity (e.g., non-disabling } \\
\text { attacks) }\end{array}$ & $\begin{array}{l}\text { - Coverage and funding for disease-modifying } \\
\text { therapies (DMTs) (government, HMOs, etc.) }\end{array}$ \\
\hline $\begin{array}{l}\text { - Failure to identify comorbid conditions influencing } \\
\text { clinical outcomes }\end{array}$ & - Radiological activity & - Lack of visit planning \\
\hline - Underestimation of patient's need & - Aversion to change & $\begin{array}{l}\text { - Lack of contingency plans for patients } \\
\text { experiencing new symptoms }\end{array}$ \\
\hline - Low tolerance to uncertainty & $\begin{array}{l}\text { - Concomitant mental illness (e.g., depression affecting } \\
\text { self-care) }\end{array}$ & $\begin{array}{l}\text { - Limited resources (e.g., MS clinic space, busy } \\
\text { schedules, low clinic, and MRI capacity) }\end{array}$ \\
\hline - Aversion to unknown risks/status quo & - Side effects of new DMTs & - High costs \\
\hline $\begin{array}{l}\text { - Herding (mistakenly following a colleague previous } \\
\text { decision) }\end{array}$ & - Poor communication & - Lack of coordination of health-care services \\
\hline - Nihilistic approach & - Lack of trust & \\
\hline $\begin{array}{l}\text { - Knowledge gaps (lack of awareness of clinical } \\
\text { guidelines) }\end{array}$ & & \\
\hline
\end{tabular}

${ }^{a}$ Adapted from Reach et al. (5) and Cooke et al. (4) with focus in MS care.

in medical decision-making. Furthermore, patients, commonly less informed about therapeutic options (e.g., efficacy and risk of side effects of DMTs), have limited tools to participate in a shared decision. This situation may lead to suboptimal treatments choices, worse clinical outcomes, and more disability (5).

Previous studies in MS care revealed that a more proactive management (e.g., including earlier use of high-efficacy DMTs and close monitoring of the clinical and radiological response to treatment) may slow the disease progression, disability, cognitive impairment, and MRI activity (6-9).

To tackle treatment inertia in MS, we might apply concepts from neuroeconomics, the science that studies the principles of how we make decisions. For example, classic studies in consumer research showed that the higher the number of available options may negatively influence consumer's decisions due to information overload (10). Moreover, the time of the day influences assertive decisions, phenomenon called "decision fatigue." Similarly, 7 out of 10 neurologists expressed TI as a result of these factors and lower tolerance to uncertainty (11). This is not surprising given that neurology practice is a medical specialty with higher incidence of physicians' biases and burnout, and MS being a neurological condition leading the paradigm of multiple therapeutic choices with ongoing developments-altogether the perfect combination for TI (https://www.medscape.com/slideshow/ lifestyle-2016-overview-6007335, accessed December 15, 2017).

This finding was also observed in previous meta-analysis including physicians (12). The authors found at least one bias in $50 \%$ of physicians. Most common identified biases include: overconfidence, lower tolerance to uncertainty, the anchoring effect, information, and availability bias (13).

Some educational strategies were developed to overcome physicians' biases. An experimental study in Rotterdam tested the benefits of reflective reasoning to diagnostic accuracy in 36 medical residents (14). Reflective reasoning is a strategy that incorporates the analysis of case scenario by identifying findings that were present or expected, and those that support or were against the diagnosis. The authors found significant improvement among second-year residents $(2.03$; 95\% CI, 1.49-2.57) and the first-year residents $(2.31 ; 95 \% \mathrm{CI}, 1.89-2.73)$ exposed to the intervention (14). A pilot study in MS care, applied the traffic light system (TLS) as an educational intervention that facilitates the decision-making process. The TLS emerged as a warning and risk categorization strategy to reduce human errors by facilitating the integration of specific situations with an action (15-18). In MS care, the goal was to match case scenarios with three types of situations according to the risk of progression: red light ("high risk"/"stop and think"), yellow light (warning, reassessment is needed), and green light ("stable"/“continue the same strategy"). The authors found this educational intervention was feasible and promising by showing a trend toward a reduction in TI compared with controls (OR 0.57; 95\% CI 0.26-1.22) (11).

Another key factor in patients' therapeutic choices relates to the application of the prospect theory (developed by Dr. Amos Tversky and Dr. Daniel Kahneman in 1979 that merit winning the Novel prize of Economy in 2002) (19). The prospect theory describes the way people choose between alternatives that involve risk, where the probabilities of outcomes are known. For example, individuals may choose $\$ 50$ for sure over the $50 \%$ probability of winning $\$ 100$ (same utility) depending on the reference point (i.e., a sure $\$ 50$ may represent a more meaningful winning to someone with a low income compared with someone wealthier). The prospect theory helps understand people choices based on their risk preferences and the reference point. This theory can be applied to MS treatment: patients with a low risk of progression or non-disabling attacked may be less willing to choose more risky (less safer) treatments, whereas those with high risk of progression may be willing to take an effective treatment that carries on a higher risk of complications (Figure 1). The EMPOWER study showed that patients' preferences in DMT selection were mainly driven by minimizing risks of side effects, the route of administration, and treatment schedule (20).

How about the treating physician? Are we ready to escalate therapy for high-risk patients when treatment goals are unmet? Studies evaluating the management of hypertension, diabetes, 


\section{How risk aversion changes according to our health status}

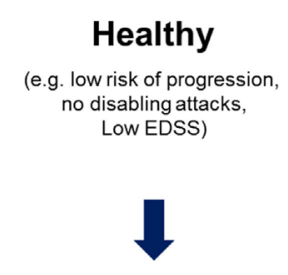

Less interested in taking risky treatments

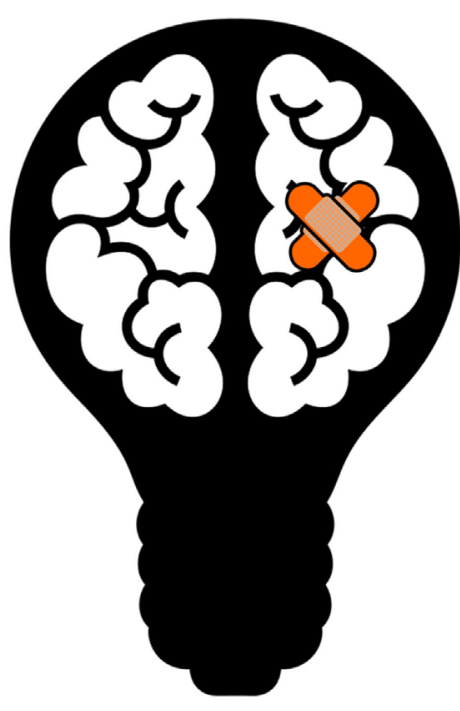

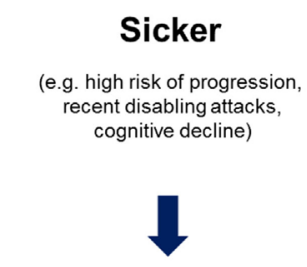

More interested in taking riskier treatments

FIGURE 1 | Application of the prospect theory to multiple sclerosis care.

atrial fibrillation, and MS suggest that $50-70 \%$ of clinicians do not escalate therapy when indicated by best practice guidelines $(3,21)$.

Finally, a third important concept is the human tendency to the status quo (tendency to maintain previous choices) and default bias (keep the option preselected by others). Common examples include individuals' tendency to keep the same insurance, phone, TV cable, or Internet provider despite other more valuable options are available. Patients and health-care providers are not immune to those biases and may miss an opportunity for improvement. On the other hand, this phenomenon may explain the appropriate resistance to escalate therapies in MS patients under uncertainty (e.g., controversial situations, unclear evidence of clinical relapses) or insurance barriers for medication switches when not clearly justified.

New treatments represent new opportunities to control MS. We, as clinicians involved in MS care, need to be aware of our own biases. More comprehensive studies that evaluate the efficacy of educational interventions to ameliorate medical errors and suboptimal therapeutic choices are needed.

Medical Schools and Scientific Institutions should be involved given the lead role in facilitating a medical education: formal training in risk management and decision-making.

\section{REFERENCES}

1. Brück W, Gold R, Lund BT, Oreja-Guevara C, Prat A, Spencer CM, et al. Therapeutic decisions in multiple sclerosis: moving beyond efficacy. JAMA Neurol (2013) 70(10):1315-24.

2. Ontaneda D, Fox RJ, Chataway J. Clinical trials in progressive multiple sclerosis: lessons learned and future perspectives. Lancet Neurol (2015) 14(2):208-23. doi:10.1016/S1474-4422(14)70264-9

3. Okonofua EC, Simpson KN, Jesri A, Rehman SU, Durkalski VL, Egan BM. Therapeutic inertia is an impediment to achieving the Healthy People
Our role as caring physicians is to provide information to our patients to facilitate therapeutic decisions. Meanwhile, our patients may have to assume a more active role in the decisionmaking process given the new paradigm in MS treatment. This broad spectrum of therapeutic choices should lead to a shared over unilateral decisions. Paraphrasing Nelson Mandela (Political leader and Philanthropist; 1918-2013): "Education is the most powerful weapon which you can use to change the world." We need to educate ourselves to guide and coach our patients toward a more informed decision process.

\section{AUTHOR CONTRIBUTIONS}

GS: study concept and design, data interpretation, manuscript drafting, and creation of tables and figures. XM: study concept, data interpretation, and supervision.

\section{FUNDING}

GS is supported by the Heart and Stroke Foundation Career Award following an open-peer reviewed competition. GS received operating grants from Roche Pharma and Boehringer Ingelheim.

2010 blood pressure control goals. Hypertension (2006) 47(3):345-51. doi:10.1161/01.HYP.0000200702.76436.4b

4. Cooke CE, Sidel M, Belletti DA, Fuhlbrigge AL. Review: clinical inertia in the management of chronic obstructive pulmonary disease. COPD (2012) 9(1):73-80. doi:10.3109/15412555.2011.631957

5. Reach G, Pechtner V, Gentilella R, Corcos A, Ceriello A. Clinical inertia and its impact on treatment intensification in people with type 2 diabetes mellitus. Diabetes Metab (2017) 43(6):501-11. doi:10.1016/j.diabet.2017.06.003

6. Noyes K, Weinstock-Guttman B. Impact of diagnosis and early treatment on the course of multiple sclerosis. Am J Manag Care (2013) 19(17 Suppl):s321-31. 
7. Sormani MP, Rio J, Tintorè M, Signori A, Li D, Cornelisse P, et al. Scoring treatment response in patients with relapsing multiple sclerosis. Mult Scler (2013) 19(5):605-12. doi:10.1177/1352458512460605

8. Duquette P, Giacomini PS, Bhan V, Hohol M, Schecter R. Balancing early aggression against risk of progression in multiple sclerosis. Can J Neurol Sci (2016) 43(1):33-43. doi:10.1017/cjn.2015.302

9. Prosperini L, Giannì C, Leonardi L, De Giglio L, Borriello G, Galgani S, et al. Escalation to natalizumab or switching among immunomodulators in relapsing multiple sclerosis. Mult Scler (2012) 18(1):64-71. doi:10.1177/ 1352458511417481

10. Iyengar SS, Lepper MR. When choice is demotivating: can one desire too much of a good thing? J Pers Soc Psychol (2000) 79(6):995-1006. doi:10.1037/ 0022-3514.79.6.995

11. Saposnik G, Maurino J, Sempere AP, Terzaghi MA, Ruff CC, Mamdani M, et al. Overcoming therapeutic inertia in multiple sclerosis care: a pilot randomized trial applying the traffic light system in medical education. Front Neurol (2017) 8:430. doi:10.3389/fneur.2017.00430

12. Blumenthal-Barby JS, Krieger H. Cognitive biases and heuristics in medical decision making: a critical review using a systematic search strategy. Med Decis Making (2015) 35(4):539-57. doi:10.1177/0272989X14547740

13. Saposnik G, Redelmeier D, Ruff CC, Tobler PN. Cognitive biases associated with medical decisions: a systematic review. BMC Med Inform Decis Mak (2016) 16(1):138. doi:10.1186/s12911-016-0377-1

14. MamedeS, van Gog T, van den BergeK, Rikers RM, van SaaseJL, van Guldener C, et al. Effect of availability bias and reflective reasoning on diagnostic accuracy among internal medicine residents. JAMA (2010) 304(11):1198-203. doi:10.1001/jama.2010.1276

15. Sonnenberg L, Gelsomin E, Levy DE, Riis J, Barraclough S, Thorndike AN. A traffic light food labeling intervention increases consumer awareness of health and healthy choices at the point-of-purchase. Prev Med (2013) 57(4):253-7. doi:10.1016/j.ypmed.2013.07.001
16. Hawley KL, Roberto CA, Bragg MA, Liu PJ, Schwartz MB, Brownell KD. The science on front-of-package food labels. Public Health Nutr (2013) 16(3):430-9. doi:10.1017/S1368980012000754

17. Murphy MS, Baker M. When used appropriately, NICE's traffic light system for febrile children helps clinicians make safe and appropriate decisions. BMJ (2014) 348:g2518. doi:10.1136/bmj.g2518

18. Orriols L, Delorme B, Gadegbeku B, Tricotel A, Contrand B, Laumon B, et al. Prescription medicines and the risk of road traffic crashes: a French registry-based study. PLoS Med (2010) 7(11):e1000366. doi:10.1371/journal. pmed. 1000366

19. Kahneman D, Tversky A. Prospect theory: an analysis of decision under risk. Econometrica (1979) 47(2):263-91. doi:10.2307/1914185

20. Arroyo R, Sempere AP, Ruiz-Beato E, Prefasi D, Carreño A, Roset M, et al. Conjoint analysis to understand preferences of patients with multiple sclerosis for disease-modifying therapy attributes in Spain: a cross-sectional observational study. BMJ Open (2017) 7(3):e014433. doi:10.1136/ bmjopen-2016-014433

21. Mohan AV, Phillips LS. Clinical inertia and uncertainty in medicine. JAMA (2011) 306(4):383; author reply-4. doi:10.1001/jama.2011.1045

Conflict of Interest Statement: The authors declare that the research was conducted in the absence of any commercial or financial relationships that could be construed as a potential conflict of interest.

Copyright (c) 2018 Saposnik and Montalban. This is an open-access article distributed under the terms of the Creative Commons Attribution License (CC $B Y)$. The use, distribution or reproduction in other forums is permitted, provided the original author(s) and the copyright owner are credited and that the original publication in this journal is cited, in accordance with accepted academic practice. No use, distribution or reproduction is permitted which does not comply with these terms. 